\title{
The European Centre for Disease Prevention and Control (ECDC) pilot point prevalence survey of healthcare-associated infections and antimicrobial use
}

P Zarb ${ }^{1,2}$, B Coignard ${ }^{3}$, J Griskeviciene ${ }^{4}$, A Muller ${ }^{2}$, V Vankerckhoven ${ }^{2}$, K Weist ${ }^{4}$, M M Goossens $^{5}$, S Vaerenberg ${ }^{5}$, S Hopkins $^{6}$,

B Catry5, D L Monnet ${ }^{4}$, H Goossens ${ }^{2}$, C Suetens (carl.suetens@ecdc.europa.eu) ${ }^{4}$, National Contact Points for the ECDC pilot point prevalence survey ${ }^{7}$, Hospital Contact Points for the ECDC pilot point prevalence survey ${ }^{7}$

1. Infection Control Unit, Mater Dei Hospital, Msida, Malta

2. Laboratory of Medical Microbiology, Vaccine and Infectious Disease Institute, University of Antwerp, Antwerp, Belgium

3. Institut de veille sanitaire, Saint-Maurice, France

4. European Centre for Disease Prevention and Control, Stockholm, Sweden

5. Scientific Institute of Public Health, Brussels, Belgium

6. Health Protection Agency, London, United Kingdom

7. The members of these groups are listed at the end of the article

Citation style for this article:

Zarb P, Coignard B, Griskeviciene J, Muller A, Vankerckhoven V, Weist K, Goossens MM, Vaerenberg S, Hopkins S, Catry B, Monnet DL, Goossens H, Suetens

$C$, National Contact Points for the ECDC pilot point prevalence survey, Hospital Contact Points for the ECDC pilot point prevalence survey. The European

Centre for Disease Prevention and Control (ECDC) pilot point prevalence survey of healthcare-associated infections and antimicrobial use. Euro Surveill.

2012;17(46):pii=20316. Available online: http://www.eurosurveillance.org/ViewArticle.aspx?Articleld=20316

A standardised methodology for a combined point prevalence survey (PPS) on healthcare-associated infections (HAIs) and antimicrobial use in European acute care hospitals developed by the European Centre for Disease Prevention and Control was piloted across Europe. Variables were collected at national, hospital and patient level in 66 hospitals from 23 countries. A patient-based and a unit-based protocol were available. Feasibility was assessed via national and hospital questionnaires. Of 19,888 surveyed patients, $7.1 \%$ had an $\mathrm{HAl}$ and $34.6 \%$ were receiving at least one antimicrobial agent. Prevalence results were highest in intensive care units, with $28.1 \%$ patients with HAI, and $61.4 \%$ patients with antimicrobial use. Pneumonia and other lower respiratory tract infections $(2.0 \%$ of patients; $95 \%$ confidence interval (Cl): $1.8-2.2 \%$ ) represented the most common type $(25.7 \%)$ of HAl. Surgical prophylaxis was the indication for $17.3 \%$ of used antimicrobials and exceeded one day in $60.7 \%$ of cases. Risk factors in the patient-based protocol were provided for $98 \%$ or more of the included patients and all were independently associated with both presence of HAI and receiving an antimicrobial agent. The patient-based protocol required more work than the unit-based protocol, but allowed collecting detailed data and analysis of risk factors for HAI and antimicrobial use.

\section{Introduction}

Healthcare-associated infections (HAls) and antimicrobial resistance are well known major public health threats. The European Centre for Disease Prevention and Control (ECDC) proposed in 2008 that the total burden of HAls should be measured regularly and in a standardised manner throughout the European Union
(EU) [1]. The initial steps towards standardisation of surveillance of HAls in Europe had been carried out on surgical site infections and infections in intensive care units by the 'Hospitals in Europe Link for Infection Control through Surveillance (HELICS)' project, from 2000 to 2003 [2-6].

Subsequently, HELICS implemented standardised surveillance of HAls in 2004 and 2005, and later as part of the 'Improving Patient Safety in Europe (IPSE)' network from 2005 to 2008 [7] which was transferred to ECDC in July 2008. Continuous surveillance, especially prospective active surveillance, is the gold standard [8]. However, repeated point prevalence surveys (PPSs) represent a more feasible alternative for hospital-wide surveillance of all HAls, while still allowing the estimation of disease burden by HAls in acute hospitals, and helping to prioritise areas requiring interventions [9]. Based on a review of 30 national or multicentre PPSs in 19 countries that had been carried out between 1996 and 2007 and included a total of 837,450 patients, ECDC estimated in 2008 the prevalence of HAls in EU acute care hospitals to be on average of $7.1 \%$ [1].

However, major methodological differences between these PPSs made comparison between countries impossible [1,10-13]. When coordination of the IPSE network was transferred to ECDC in July 2008, ECDC recommended that surveillance in the EU should include all types of HAls. Subsequently, the ECDC prepared a protocol for a PPS of HAls in acute care hospitals, which was finalised in March 2011 [14].

Although most antimicrobials are prescribed in the community [15], the selective pressure they exert is 
much higher in hospitals, where the proportion of patients receiving antimicrobial agents is much higher there than in the community [16]. This is considered to be the main reason why microorganisms isolated from hospital infections show more resistant profiles than microorganisms from community infections [17]. Various hospital PPSs on antimicrobial use were carried out in the last three decades [18-22]. Also these PPS varied greatly in aims, protocols and populations surveyed, thus making comparison of their results difficult. The 'European Surveillance of Antimicrobial Consumption (ESAC)' project initiated standardisation of the methodology for measuring antimicrobial consumption across Europe [23-26]. This methodology has proven feasible and reliable $[24,25,27]$. In view of the transition of the ESAC network to ECDC in July 2011, the ESAC methodology for PPS of antimicrobial use was integrated as part of an ECDC protocol for PPS of HAls and antimicrobial use in acute care hospitals. Combined PPSs of HAls and antimicrobial use had also previously been carried out in different populations [28-32], but again with large methodological differences between surveys.

The main aim of this ECDC pilot PPS was to test a common European methodology for PPSs of HAls and antimicrobial use in acute care hospitals before its implementation across the EU, with the specific objectives to estimate the total burden of HAls and antimicrobial use and disseminate the results at local, regional, national and EU level. The ECDC pilot PPS protocol met the objectives of the Council Recommendation of 9 June 2009 on patient safety, including the prevention and control of HAls (2009/C 151/01), and specifically article II.8.c of this recommendation, i.e. "to establish or strengthen active surveillance at institution, regional and national level" [33]. In addition, the ECDC pilot PPS also met the objectives of Council Recommendation of 15 November 2001 on the prudent use of antimicrobial agents in human medicine (2002/77/EC) [34].

\section{Methods}

Participating countries and hospitals

In January 2010, ECDC invited all national contact points for HAI surveillance and/or experts designated as national expert for the ECDC PPS to participate in the pilot PPS study and enter at least one institution qualified as acute care hospital according to national definitions. Two or more hospitals per country were preferred to allow testing of both the patient-based ('standard') and unit-based ('light') version of the protocol in the same country. In total, 23 countries (22 EU Member States and one EU enlargement country) participated in the survey with 66 hospitals and including 19,888 patients.

The number of hospitals per country was: Belgium ( $n=7$ hospitals), Bulgaria $(n=2)$, Croatia $(n=2)$, Cyprus $(n=3)$, Czech Republic $(n=2)$, Estonia $(n=2)$, Finland $(n=16)$, France $(n=3)$, Germany $(n=1)$, Greece $(n=1)$, Hungary $(n=2)$, Italy $(n=4)$, Latvia $(n=2)$, Lithuania $(n=3)$, Luxembourg $(n=1)$, Malta $(n=1)$, Poland $(n=1)$, Portugal $(n=2)$, Romania $(n=1)$, Slovakia $(n=2)$, Slovenia $(n=2)$, Spain $(n=5)$, and the United Kingdom, Scotland $(n=1)$.

The national contact points acted as national PPS coordinators and invited hospitals to participate on a voluntary basis. As this was a pilot survey, we did not aim for a representative sample of hospitals in the countries. It was recommended to include both large and small hospitals in order to test the feasibility of the protocol in different settings. Information on the size and type (primary, secondary, tertiary and specialised) of each hospital was collected through a specific hospital questionnaire. National questionnaires were used to collect data on the number of acute care hospitals and beds for the entire country and by hospital type.

\section{Case definitions}

European case definitions for HAls were used where these had been developed previously by HELICS or other European projects [35-38], whereas case definitions from the National Healthcare Safety Network (NHSN, formerly NNIS) at the United States Centers for Disease Control and Prevention (CDC) were used otherwise $[39,40]$. In the HAl section, data on microorganisms and the respective resistant phenotype were collected. Only results that were already available on the date of the survey were included.

For the purposes of this protocol, an infection was defined as active on the day of the survey when:

1. signs and symptoms were present on the date of the survey;

OR

2. signs and symptoms were no longer present but the patient was still receiving treatment for that infection on the date of the survey. In this case, the symptoms and signs occurring from the start of treatment until the date of the survey were checked to ascertain that the infection matched one of the case definitions of HAl.

An active infection was defined as healthcare-associated (associated to acute care hospital stay only, for the purpose of this protocol) when:

1. the onset of the signs and symptoms was on Day 3 of the current admission or later (with Day 1 the day of admission);

OR

2. the signs and symptoms were present at admission or became apparent before Day 3, but the patient had been discharged from an acute care hospital less than two days before admission;

OR

3. the signs and symptoms of an active surgical site infection were present at admission or started before Day 3, and the surgical site infection occurred within 30 days of a surgical intervention (or in the case of 
surgery involving an implant, a deep or organ/space surgical site infection that developed within a year of the intervention);

$\mathrm{OR}$

4. the signs and symptoms of a Clostridium difficile infection were present at admission or started before Day 3, with the patient having been discharged from an acute care hospital less than 28 days before the current admission.

For antimicrobial use, the Anatomical Therapeutic Chemical (ATC) classification system of the World Health Organization Collaborating Centre for Drug Statistics Methodology was used [41]. Antimicrobial agents for systemic use within the ATC groups Ao7AA (intestinal anti-infectives), Do1BA (dermatological antifungals for systemic use), Jo1 (antibacterials for systemic use), Jo2 (antimycotics for systemic use), J04AB02 (rifampicin) and P01AB (nitroimidazole-derived antiprotozoals) were included. Antiviral agents and antimicrobials for the treatment of tuberculosis were not included.

As in the former ESAC hospital PPS protocol [23-26], antimicrobial treatment was recorded if, at the time of survey, the antimicrobial agent was still prescribed on the treatment chart. In the case of surgical prophylaxis, any single dose of an antimicrobial agent given within the 24-hour period before 8:00 am on the day of the survey was recorded. This time window for surgical prophylaxis allowed making the distinction between single dose prophylaxis, one day prophylaxis, or prophylactic doses given over more than one day.

\section{Data collection and inclusion criteria}

Two data collection protocols were available for use by participating hospitals. The first was patient-based: Denominator data, including risk factors, were collected for each individual patient irrespective of whether the patient had a $\mathrm{HAl}$ and/or received antimicrobials. The patient form for this protocol also included more detailed information, such as the presence of invasive devices, the specialty area of the patient's disease or consultant in charge of the patient and the McCabe score (the McCabe score classifies the severity of underlying medical conditions) [42]. The second protocol was unit-based: Denominator data were aggregated at ward level, and a patient form was used only for patients with a HAI and/or receiving antimicrobials. For both protocols, data were also collected at both ward level (ward name and specialty) and hospital level, including hospital type, size and whether or not any wards were excluded from the survey.

Each participating hospital had to choose one of the two data collection protocols. For each ward, all patients registered on the ward census before 8:00 am and not discharged from the ward at the time of the survey were assessed. Patients who were temporarily absent from the ward (e.g. for medical imaging, endoscopy, surgery) were included in the survey. Day admissions, outpatients (including patients attending the hospital for haemodialysis) and patients at the Accident and Emergency department were excluded. In addition, given that the agreed objective of the EU-wide ECDC PPS was to estimate the burden of HAls and antimicrobial use in acute care hospitals only, long-term care units in acute care hospitals were excluded from the survey; however, long-term patients within an acute care ward were included. It was recommended that each participating hospital should include all eligible patients in the survey. Despite this recommendation, five of the 66 hospitals excluded one or several wards that were eligible for inclusion, because the hospital staff considered that being exhaustive was not needed for a pilot study.

The ECDC pilot PPS protocol recommended that personnel experienced in reading patient charts/notes and in identifying HAls (e.g. infection control professionals, clinical microbiologists, infectious disease physicians) should act as survey team leaders in the hospitals. To obtain better information, collaboration with the clinical team in charge of patient care was recommended rather than exclusively reading the patient chart/notes and laboratory results. The number and type of healthcare workers (HCWs) performing the PPS in the hospital was assessed by questionnaire.

Data collectors in the hospital were trained by the national PPS coordinators to become familiar with the protocol and case definitions. Training material in English language was provided by ECDC through a contract with the Health Protection Agency, London (contract ECD.1842).

\section{Time window}

The ECDC pilot PPS had to be carried out any time between May and October 2010. The ideal duration of a 'point' prevalence survey is a single day but this was not feasible for the majority of participants due to the size of the hospital and/or the lack of trained personnel. To ensure feasibility of the survey, the maximum total time allowed to complete data collection in each hospital was three weeks and preferably not more than two weeks. Each individual ward, and if possible each respective department (e.g. all medical wards), had to be surveyed on the same day.

\section{Data entry}

Each country was free to organise its own system for data entry and processing, as long as all variables were collected in accordance with the ECDC methodology. It was not possible for a hospital to use a mixture of the patient-based and unit-based protocols. Most hospitals entered their data directly into an adapted version of the ESAC WebPPS located on the server of the University of Antwerp [24,25]. Only one country (Slovenia), participating with two hospitals, used its local software, whilst Belgium used the WebPPS installed on the server of the Belgian Scientific Institute for Public Health (WIV-ISP) in Brussels. Belgian data were uploaded on the WIV-ISP server and were 
later incorporated into the European data set at the University of Antwerp. Data from Slovenia were converted by ECDC and then transferred to the University of Antwerp for incorporation into the central database.

\section{Feasibility and workload}

An additional feasibility questionnaire was sent to the national contact points of the 23 participating countries and to the corresponding 66 hospital contact points. At the national level, we requested information about whether a list of hospitals by type (primary, secondary, tertiary and specialised) and size was available, thus assessing the feasibility of a systematic sampling design using these variables in future surveys. National contact points were also asked to give any other feedback regarding the feasibility of obtaining a representative sample of hospitals in their country. In addition, data about the workload needed for training, data collection and data entry were requested both at the national and hospital level. The number and type of HCWs involved in the survey were also collected.

\section{Data analysis}

Data were analysed at the University of Antwerp and at ECDC using Stata 10.1 (StataCorp Texas, US). Binomial exact confidence limits were calculated where appropriate. Risk factor analysis was performed separately for HAls and for antimicrobial use using multiple logistic regression. Presence of a peripheral and central vascular catheter were excluded from the multiple logistic regression model since the time relationship between insertion of a catheter and start of parenteral antimicrobial use cannot be deduced from the protocol. In both models, $\mathrm{p}$ values below 0.05 were considered as statistically significant. Individual hospital reports (Microsoft Excel spreadsheets) summarising the hospital's prevalence figures, compared to the aggregated prevalence figures of all participating hospitals in the country, were produced by ECDC using Stata 10.1 and sent to the national contact points for further distribution and feedback to the hospital contact points. We did not receive any feedback from the hospitals that these reports were not concordant with local hospital data.

\section{Results}

A total of 19,888 patients from 66 hospitals in 23 countries were included in the ECDC pilot PPS. Fifty hospitals used the patient-based protocol and 16 hospitals used the unit-based protocol.

Hospital characteristics were available for 65 hospitals. University or other teaching hospitals (defined as 'tertiary' hospitals in the protocol) represented $52.3 \%$ of participating hospitals, secondary hospitals $24.6 \%$, primary hospitals $15.4 \%$ and specialised hospitals $7.7 \%$, with an average hospital size of 614 beds, 431 beds, 215 beds and 300 beds, respectively. The overall average hospital size in the study sample was 483 beds (median: 400 beds). At national level, only 13 countries (representing 29 hospitals in the study sample) were able to provide national numbers of hospitals by type. Tertiary hospitals represented $7.7 \%$ of all acute care hospitals in these countries, secondary hospitals $31.1 \%$, primary hospitals $49.3 \%$ and specialised hospitals $11.9 \%$. The total number of hospitals in these 13 countries was 2,609 with on average 298

\section{TABLE 1}

Prevalence of healthcare-associated infections and antimicrobial use in surveyed patients, by specialty, during the ECDC pilot point prevalence survey, $2010(n=19,888)$

\begin{tabular}{|c|c|c|c|c|c|c|}
\hline \multirow{2}{*}{ Specialty } & \multicolumn{2}{|c|}{ Surveyed patients } & \multicolumn{2}{|c|}{ Patients with $\mathrm{HAl}^{\mathrm{a}}$} & \multicolumn{2}{|c|}{ Patients with antimicrobial use } \\
\hline & $n^{c}$ & $\%^{d}$ & $\mathrm{n}^{\mathrm{c}}$ & $\% \mathrm{e}^{\mathrm{e}}$ & $\mathrm{n}^{\mathrm{c}}$ & $\%{ }^{e}$ \\
\hline Surgery & 6,653 & 33.5 & 518 & 7.8 & 2,584 & 38.8 \\
\hline Medicine & 7,833 & 39.4 & 505 & 6.4 & 2,888 & 36.9 \\
\hline Paediatrics & 1,024 & 5.1 & 38 & 3.7 & 310 & 30.3 \\
\hline Intensive care & 915 & 4.6 & 257 & 28.1 & 562 & 61.4 \\
\hline Obstetrics and Gynaecology & 1,711 & 8.6 & 32 & 1.9 & 313 & 18.3 \\
\hline Geriatrics & 502 & 2.5 & 33 & 6.6 & 117 & 23.3 \\
\hline Psychiatry & 828 & 4.2 & 2 & 0.2 & 18 & 2.2 \\
\hline Other/mixed & 422 & 2.1 & 23 & 5.5 & 83 & 19.7 \\
\hline All specialties & 19,888 & 100 & 1,408 & 7.1 & 6,875 & 34.6 \\
\hline
\end{tabular}

ECDC: European Centre for Disease Prevention and Control; HAI: healthcare-associated infection.

\footnotetext{
Patients with a least one HAI.

b Patients receiving at least one antimicrobial agent.

Number of patients in category.

Percentage of total (column percent).

Percentage within category (category percent).
} 
beds (median: 261 beds), for a total population of 160 million inhabitants in 2010.

\section{Healthcare-associated infections}

Overall, $7.1 \%$ patients had at least one $\mathrm{HAI}$, ranging from $0.2 \%$ in psychiatry to $28.1 \%$ in intensive care departments (Table 1). The prevalence of HAls was $5.8 \%$ in primary hospitals, $6.3 \%$ in secondary hospitals, $7.4 \%$ in tertiary hospitals and $7.8 \%$ in specialised hospitals.

The most common type of HAl was pneumonia and other lower respiratory tract infections, representing $\mathbf{2 5 . 7} \%$ of all reported HAls (Table 2 ). The second most frequently reported type of HAI was surgical site infection (18.9\%), followed by urinary tract infection (17.2\%), bloodstream infection (14.2\%) and gastro-intestinal infection (7.8\%). Clostridium difficile infections represented $1.4 \%$ of all HAls. On average, there were 1.09 HAls per infected patient (or a total of 1,531 HAls in 1,408 patients with $\mathrm{HAl}$ ). The median length of stay before onset of HAl acquired during the current hospitalisation ( $n=1,159)$ was 12 days (range: $4-65$ days). Of 372 (24\%) HAls present at admission, $58 \%$ were associated with a previous stay in the same hospital.

For $59.1 \%$ of the HAls, a positive microbiology result was available, ranging from $40.3 \%$ for gastro-intestinal infections to $94.0 \%$ in bloodstream infections (Table 3).

The most commonly isolated groups of microorganisms were Gram-negative non-Enterobacteriaceae in pneumonia (36.5\%), Enterobacteriaceae in urinary tract infections $(63.8 \%)$ and Gram-positive cocci in surgical site infections (54.3\%). Overall, the most commonly isolated microorganism was Escherichia coli $(15.2 \%$ overall, and $37.1 \%$ in urinary tract infections), followed by Staphylococcus aureus $(12.1 \%$ overall and $21.5 \%$ in surgical site infections).

Carbapenem resistance was reported in $3.2 \%$ of Enterobacteriaceae, $23.4 \%$ of Pseudomonas aeruginosa and $20.4 \%$ of Acinetobacter spp. The percentage of meticillin-resistant S. aureus (MRSA) was $34.2 \%$ and that of glycopeptide-resistant Enterococcus spp. was $5.4 \%$.

\section{Antimicrobial use}

A total of 6,875 patients (34.6\%) received at least one antimicrobial agent at the time of the survey, ranging from $2.2 \%$ in psychiatry to $61.4 \%$ in intensive care departments (Table 1). The prevalence of antimicrobial use was $36.2 \%$ in primary hospitals, $32.1 \%$ in secondary hospitals, $35.7 \%$ in tertiary hospitals and $28.7 \%$ in specialised hospitals. Analysing the antimicrobial agents used by main indication (treatment, surgical prophylaxis and medical prophylaxis) revealed differences in the use of different antimicrobial classes (Table 4).
Pneumonia or other lower respiratory tract infection was the most common indication (29.2\%) for antimicrobial treatment, and accounted for $31.6 \%$ of intentions for treatment of community infection, and $24.8 \%$ of intentions for treatment of hospital infection.

The most widely used antimicrobial agents at ATC 4th level were combinations of penicillins with beta-lactamase inhibitors (16.3\%), mainly for treatment intention (18.0\%). For surgical prophylaxis, first- and secondgeneration cephalosporins were mostly chosen: $26.8 \%$ and $20.0 \%$, respectively. For medical prophylaxis, fluoroquinolones, primarily ciprofloxacin, were the most widely used antimicrobial agents.

Table 5 summarises the indications for antimicrobial use, their route of administration and whether the reason for antimicrobial use was indicated on the patient chart. Community infection was the most common treatment intention ( $41.3 \%)$, followed by hospital infection (24.0\%). Surgical prophylaxis (17.3\%) was prolonged for more than one day in $60.7 \%$ of cases. Medical prophylaxis accounted for $13.5 \%$ of antimicrobial use. The parenteral route of administration was used for $71.9 \%$ of administered antimicrobial agents. A reason was included in the chart of $69.3 \%$ of the patients on antimicrobials (Table 5 ).

\section{Risk factors}

Data from the 50 hospitals that used the patient-based protocol, including patient characteristics and risk factors, are shown in Table 6. Using multiple logistic regression, the presence of an HAl was independently associated with age (highest adjusted odds ratio in children under five years-old, p<0.001), male sex ( $p<0.05$ ), length of stay before onset of HAI ( $p$ for trend<0.001), the McCabe score ( $p$ for trend<0.001), the number of invasive devices (urinary catheter and intubation) before onset of infection ( $p$ for trend<0.001) and surgery since admission ( $p<0.001)$. Antimicrobial use was independently associated with age (highest adjusted odds ratio in the age category 1-4 years, $p<0.001)$, male sex ( $p<0.001)$, the McCabe score ( $p$ for trend<0.001), the number of invasive devices (urinary catheter and intubation, $p$ for trend 0.001 ), length of stay in the hospital ( $p$ for trend<0.05) and surgery since admission ( $p<0.001$ ).

\section{Feasibility}

Thirteen countries (Belgium, Bulgaria, Cyprus, Estonia, France, Greece, Italy, Lithuania, Malta, Portugal, Romania, Slovakia and Spain) responded to the national feasibility questionnaire. Fifty hospitals responded to the hospital feasibility questionnaire.

Overall, the average number of HCW involved in data collection, excluding ward staff, was six, with a maximum of 21 . In five hospitals, one single HCW was involved in the data collection process. Ward staff was involved in 20 hospitals. On average per hospital, 3,7 different types of HCW were involved in the survey for 


\section{TABLE 2}

Prevalence of healthcare-associated infections and antimicrobial use in surveyed patients, by specialty, during the ECDC pilot point prevalence survey, $2010(n=19,888)$

\begin{tabular}{|c|c|c|c|c|c|c|c|c|c|c|}
\hline \multirow{3}{*}{ Type of infection } & \multirow{2}{*}{\multicolumn{4}{|c|}{ HAls }} & \multicolumn{6}{|c|}{ Antimicrobial use (treatment only)a } \\
\hline & & & & & \multicolumn{2}{|c|}{$\begin{array}{l}\text { All treatment } \\
\text { intentions }^{\mathrm{b}}\end{array}$} & \multicolumn{2}{|c|}{$\begin{array}{l}\text { Treatment intended } \\
\text { for community } \\
\text { infection }\end{array}$} & \multicolumn{2}{|c|}{$\begin{array}{l}\text { Treatment intended } \\
\text { for hospital }\end{array}$} \\
\hline & $\stackrel{n}{\text { patients }^{c}}$ & $\begin{array}{c}\% \\
\text { patients } \\
{[95 \% \mathrm{Cl}]^{\mathrm{d}}}\end{array}$ & $\stackrel{n}{\text { HAIs }^{e}}$ & $\begin{array}{l}\text { Relative } \\
\% \text { HAls }^{f}\end{array}$ & $\begin{array}{c}\mathrm{n} \\
\text { intentions }\end{array}$ & $\begin{array}{l}\text { Relative } \\
\%\end{array}$ & $\begin{array}{c}\mathrm{n} \\
\text { intentions }\end{array}$ & $\begin{array}{l}\text { Relative } \\
\%\end{array}$ & $\begin{array}{c}\mathrm{n} \\
\text { intentions }\end{array}$ & $\begin{array}{l}\text { Relative } \\
\%\end{array}$ \\
\hline $\begin{array}{l}\text { Pneumonia or other } \\
\text { lower respiratory tract } \\
\text { infection }\end{array}$ & 392 & $\begin{array}{c}2.0 \\
{[1.8-2.2]}\end{array}$ & 394 & $25 \cdot 7$ & 1,328 & 29.2 & 922 & 31.6 & 382 & 24.8 \\
\hline Surgical site infection & 290 & {$\left[1.3^{1.5}-1.6\right]$} & 290 & 18.9 & $-g$ & $-g$ & $-g$ & $-g$ & $-\mathrm{g}$ & $-\mathrm{g}$ \\
\hline Urinary tract infection & 263 & {$\left[\begin{array}{c}1.3 \\
{[1.2-1.5]}\end{array}\right.$} & 264 & 17.2 & 679 & 14.9 & 412 & 14.1 & 237 & $15 \cdot 4$ \\
\hline $\begin{array}{l}\text { Bloodstream infection } \\
(B S I)^{\mathrm{h}}\end{array}$ & 216 & {$\left[\begin{array}{c}1.1 \\
{[0.9-1.2]}\end{array}\right.$} & 217 & 14.2 & 219 & 4.8 & 67 & 2.3 & 145 & $9 \cdot 4$ \\
\hline $\begin{array}{l}\text { Gastrointestinal } \\
\text { infection }\end{array}$ & 118 & $\begin{array}{c}0.6 \\
{[0.5-0.7]}\end{array}$ & 119 & 7.8 & 593 & 13.0 & 466 & 16.0 & 117 & 7.6 \\
\hline $\begin{array}{l}\text { Skin and soft tissue } \\
\text { infection }\end{array}$ & 59 & {$\left[\begin{array}{c}0.3 \\
{[0.2-0.4]}\end{array}\right.$} & 59 & 3.9 & 646 & 14.2 & 357 & 12.2 & 279 & 18.1 \\
\hline $\begin{array}{l}\text { Bone or joint } \\
\text { infection }\end{array}$ & 38 & $\begin{array}{c}0.2 \\
{[0.1-0.3]}\end{array}$ & 39 & 2.5 & 154 & 3.4 & 92 & 3.2 & 60 & 3.9 \\
\hline $\begin{array}{l}\text { Eye, ear, nose or } \\
\text { mouth infection }\end{array}$ & 47 & $\begin{array}{c}0.2 \\
{[0.2-0.3]}\end{array}$ & 47 & 3.1 & 211 & 4.6 & 170 & 5.8 & 41 & 2.7 \\
\hline Systemic infection ${ }^{h}$ & 40 & $\begin{array}{c}0.2 \\
{[0.1-0.3]}\end{array}$ & 40 & 2.6 & 668 & 14.7 & 318 & 10.9 & 334 & 21.7 \\
\hline $\begin{array}{l}\text { Cardiovascular } \\
\text { system infection }\end{array}$ & 26 & $\begin{array}{c}0.1 \\
{[0.1-0.2]}\end{array}$ & 26 & 1.7 & 76 & 1.7 & 40 & 1.4 & 36 & 2.3 \\
\hline $\begin{array}{l}\text { Central nervous } \\
\text { system infection }\end{array}$ & 15 & {$\left[\begin{array}{c}0.1 \\
{[0.0-0.1]}\end{array}\right.$} & 15 & 1.0 & 67 & 1.5 & 54 & 1.8 & 12 & 0.8 \\
\hline $\begin{array}{l}\text { Catheter-related } \\
\text { infections without } \\
\text { bloodstream infection }\end{array}$ & 11 & $\begin{array}{c}0.1 \\
{[0.0-0.1]}\end{array}$ & 11 & 0.7 & $-\mathrm{g}$ & $-g$ & $-\mathrm{g}$ & $-g$ & $-\mathrm{g}$ & $-g$ \\
\hline $\begin{array}{l}\text { Reproductive tract } \\
\text { infection }\end{array}$ & 10 & {$\left[\begin{array}{c}0.1 \\
{[0.0-0.1]}\end{array}\right.$} & 10 & 0.7 & 65 & 1.4 & 49 & 1.7 & 16 & 1.0 \\
\hline Missing/unknown & 0 & NA & NA & NA & 65 & 1.4 & 39 & 1.3 & 25 & 1.6 \\
\hline Total & 1,408 & $\begin{array}{c}7.1 \\
{[6.7-7.5]}\end{array}$ & 1,531 & 100 & 4,552 & 100 & 2,919 & 100 & 1,539 & 100 \\
\hline
\end{tabular}

CI: confidence interval; ECDC: European Centre for Disease Prevention and Control; HAI: healthcare-associated infection; NA: not applicable.

a This table does not include antimicrobials used for prophylaxis or for unknown indications (shown in Table 5).

b The category "Treatment intended for infections acquired in long-term care facilities" represented $2.0 \%$ of all treatment intentions and is not shown in the table.

c Number of patients with HAI (site-specific number)

d Percentage of patients with HAI (site-specific prevalence)

e Number of HAls.

$f$ Percentage of total number of HAls (relative percentage)

$g$ For used antimicrobials, the types of infection 'surgical site infection' and 'catheter-related infection without bloodstream infection' were not specifically recorded and could be included within the category 'skin and soft tissue infection'.

h Includes catheter-related infections with positive blood culture, and neonatal bloodstream infections and clinical sepsis. For used antimicrobials, some bloodstream infections (bacteraemia) may have been included in the category 'systemic infection'. 


\section{TABLE 3}

Distribution of microorganisms isolated in healthcare-associated infections, by main type of infection, ECDC pilot point prevalence survey, $2010(\mathrm{n}=1,165)$

\begin{tabular}{|c|c|c|c|c|c|c|}
\hline & $\begin{array}{l}\text { All types of } \\
\text { infection }\end{array}$ & $\begin{array}{l}\text { Pneumonia or } \\
\text { other lower } \\
\text { respiratory tract } \\
\text { infection }\end{array}$ & $\begin{array}{l}\text { Surgical site } \\
\text { infection }\end{array}$ & $\begin{array}{l}\text { Urinary tract } \\
\text { infection }\end{array}$ & $\begin{array}{l}\text { Bloodstream } \\
\text { infection }\end{array}$ & $\begin{array}{l}\text { Gastrointestinal } \\
\text { infection }\end{array}$ \\
\hline & n (\%) & n (\%) & n (\%) & n (\%) & n (\%) & n (\%) \\
\hline \multicolumn{7}{|l|}{ HAls and microorganisms } \\
\hline HAls, total & $1,531(100)$ & $394(25.7)$ & $290(18.9)$ & $264(17.2)$ & $200(13.1)$ & $119(7.8)$ \\
\hline HAls with microorganisms & $905(59.1)$ & $191(48.5)$ & $172(59.3)$ & $187(70.8)$ & $188(94.0)$ & $48(40.3)$ \\
\hline Microorganisms, total & $1,165(100)$ & $249(100)$ & $247(100)$ & $210(100)$ & $228(100)$ & $65(100)$ \\
\hline \multicolumn{7}{|l|}{ Major groups of microorganisms } \\
\hline Gram-positive cocci & $410(35.2)$ & $46(18.5)$ & $134(54 \cdot 3)$ & $39(18.6)$ & $95(41.7)$ & $21(32.3)$ \\
\hline Enterobacteriaceae & $404(34.7)$ & $80(32.1)$ & $58(23.5)$ & $134(63.8)$ & $79(34.7)$ & $18(27.7)$ \\
\hline $\begin{array}{l}\text { Gram-negative bacteria, } \\
\text { non-Enterobacteriaceae }\end{array}$ & $226(19 \cdot 4)$ & $91(36.5)$ & $36(14.6)$ & $29(13.8)$ & $30(13.2)$ & $7(10.8)$ \\
\hline Fungi & $69(5.9)$ & $23(9.2)$ & $5(2.0)$ & $7(3 \cdot 3)$ & $17(7.5)$ & $4(6.2)$ \\
\hline \multicolumn{7}{|c|}{ Top 15 microorganisms (accounting for ( $92.4 \%$ of total number microorganisms) } \\
\hline Escherichia coli & $177(15.2)$ & $24(9.6)$ & $29(11.7)$ & $78(37.1)$ & $29(12.7)$ & $10(15 \cdot 4)$ \\
\hline Staphylococcus aureus & $141(12.1)$ & $26(10.4)$ & $53(21.5)$ & $2(1.0)$ & $26(11.4)$ & $5(7.7)$ \\
\hline Pseudomonas aeruginosa & $131(11.2)$ & $44(17.7)$ & $24(9.7)$ & $21(10.0)$ & $17(7 \cdot 5)$ & $6(9.2)$ \\
\hline Enterococcus spp. & $114(9.8)$ & $4(1.6)$ & $33(13 \cdot 4)$ & $32(15.2)$ & $21(9.2)$ & $11(16.9)$ \\
\hline $\begin{array}{l}\text { Coagulase-negative } \\
\text { staphylococci }\end{array}$ & $97(8.3)$ & $3(1.2)$ & $33(13 \cdot 4)$ & $3(1.4)$ & $38(16.7)$ & $1(1.5)$ \\
\hline Klebsiella spp. & $94(8.1)$ & $22(8.8)$ & $7(2.8)$ & $30(14 \cdot 3)$ & $25(11.0)$ & $3(4.6)$ \\
\hline Candida spp. & $56(4.8)$ & $15(6.0)$ & $3(1.2)$ & $6(2.9)$ & $16(7.0)$ & $3(4.6)$ \\
\hline Enterobacter spp. & $49(4.2)$ & $13(5.2)$ & $10(4.0)$ & $6(2.9)$ & $10(4 \cdot 4)$ & $1(1.5)$ \\
\hline Acinetobacter spp. & $49(4.2)$ & $18(7.2)$ & $5(2.0)$ & $5(2.4)$ & $9(4.0)$ & $1(1.5)$ \\
\hline Streptococcus spp. & $45(3.9)$ & $13(5.2)$ & $11(4 \cdot 5)$ & $2(1.0)$ & $4(1.8)$ & $4(6.2)$ \\
\hline Proteus spp. & $35(3.0)$ & $5(2.0)$ & $6(2.4)$ & $15(7.1)$ & $4(1.8)$ & $0(0)$ \\
\hline Anaerobic bacilli & $24(2.1)$ & $1(0.4)$ & $5(2.0)$ & $\mathrm{o}(0)$ & $5(2.2)$ & $11(16.9)$ \\
\hline Serratia spp. & $17(1.5)$ & $11(4 \cdot 4)$ & $1(0.4)$ & $0(0)$ & $5(2.2)$ & $0(0)$ \\
\hline Other Enterobacteriaceae & $17(1.5)$ & $3(1.2)$ & $\mathrm{o}(0)$ & $1(0.5)$ & $4(1.8)$ & $3(4.6)$ \\
\hline Stenotrophomonas maltophilia & $16(1.4)$ & $11(4 \cdot 4)$ & $3(1.2)$ & o (o) & $1(0.4)$ & o (o) \\
\hline Citrobacter spp. & $15(1.3)$ & $2(0.8)$ & $5(2.0)$ & $4(1.9)$ & $2(0.9)$ & $1(1.5)$ \\
\hline
\end{tabular}

ECDC: European Centre for Disease Prevention and Control; HAI: healthcare-associated infection.

The table only shows details for the main infection types. The total also includes all other HAI types. 
TABLE 4

Distribution of antimicrobial agents (ATC 4th and 5th levels) by main indication for use, ECDC pilot point prevalence survey, 2010 ( $n=9,588$ antimicrobial agents)

\begin{tabular}{|c|c|c|c|c|}
\hline & All indications & Treatment & $\begin{array}{c}\text { Surgical } \\
\text { prophylaxis }\end{array}$ & $\begin{array}{c}\text { Medical } \\
\text { prophylaxis }\end{array}$ \\
\hline & n (\%) & n (\%) & $\mathrm{n}(\%)$ & $\mathrm{n}(\%)$ \\
\hline Antimicrobial agents, total & $9,588(100)$ & $6,365(100)$ & $1,654(100)$ & $1,293(100)$ \\
\hline \multicolumn{5}{|l|}{ Top antimicrobial agents at ATC 4 th level (accounting for $93.1 \%$ of use) } \\
\hline Combinations of penicillins, incl. beta-lactamase inhibitors (Jo1CR) & $1,566(16.3)$ & $1,147(18.0)$ & $217(13.1)$ & $145(11.2)$ \\
\hline Fluoroquinolones (Jo1MA) & $1,293(13.5)$ & $948(14.9)$ & $133(8.0)$ & $168(13.2)$ \\
\hline Second-generation cephalosporins (Jo1DC) & $900(9.4)$ & $475(7.5)$ & $330(20.0)$ & $76(5.9)$ \\
\hline Third-generation cephalosporins (Jo1DD) & $701(7.3)$ & $521(8.2)$ & $94(5.7)$ & $67(5.2)$ \\
\hline First-generation cephalosporins (Jo1DB) & $599(6.2)$ & $121(1.9)$ & $444(26.8)$ & $23(1.8)$ \\
\hline Carbapenems (Jo1DH) & $583(6.1)$ & $503(7.9)$ & $25(1.5)$ & $37(2.9)$ \\
\hline Imidazole derivatives (Jo1XD) & $494(5.2)$ & $278(4.4)$ & $151(9.1)$ & $51(3.9)$ \\
\hline Glycopeptide antibacterials (Jo1XA) & $449(4.7)$ & $365(5.7)$ & $41(2.5)$ & $31(2.4)$ \\
\hline Aminoglycosides (Jo1GB) & $427(4.5)$ & $277(4.4)$ & $72(4.4)$ & $69(5.3)$ \\
\hline Triazole derivatives (Jo2AC) & $424(4.4)$ & $246(3.9)$ & $11(0.7)$ & $153(11.8)$ \\
\hline Penicillins, extended spectrum without anti-pseudomonal activity (Jo1CA) & $289(3.0)$ & $200(3.1)$ & $18(1.1)$ & $65(5.0)$ \\
\hline Combinations of sulfonamides and trimethoprim, incl. derivatives (J01EE) & $252(2.6)$ & $70(1.1)$ & $7(0.4)$ & $163(12.6)$ \\
\hline Lincosamides (Jo1FF) & $232(2.4)$ & $183(2.9)$ & $38(2.3)$ & $11(0.9)$ \\
\hline Macrolides (J01FA) & $185(1.9)$ & $144(2.3)$ & $4(0.2)$ & $26(2.0)$ \\
\hline Beta-lactamase-resistant penicillins (Jo1CF) & $160(1.7)$ & $138(2.2)$ & $16(1.0)$ & $5(0.4)$ \\
\hline Nitroimidazole derivatives (P01AB) & $134(1.4)$ & $102(1.6)$ & $17(1.0)$ & $9(0.7)$ \\
\hline Beta-lactamase-sensitive penicillins (Jo1CE) & $133(1.4)$ & $90(1.4)$ & $9(0.5)$ & $32(2.5)$ \\
\hline Other antibacterials (Jo1XX) & $102(1.1)$ & $80(1.3)$ & $4(0.2)$ & $11(0.9)$ \\
\hline \multicolumn{5}{|l|}{ Top antimicrobial agents at ATC 5 th level (accounting for $70.8 \%$ of use) } \\
\hline Amoxicillin and enzyme inhibitor (J01CRo2) & $1,045(10.9)$ & $696(10.9)$ & $193(11.7)$ & $104(8.0)$ \\
\hline Cefuroxime (Jo1DCo2) & $866(9.0)$ & $466(7.3)$ & $318(19.2)$ & $63(4.9)$ \\
\hline Ciprofloxacin (J01MA02) & $844(8.8)$ & $607(9.5)$ & $100(6.0)$ & $113(8.7)$ \\
\hline Metronidazole (Jo1XDo1) & $493(5.1)$ & $277(4.4)$ & $151(9.1)$ & $51(3.9)$ \\
\hline Cefazolin (Jo1DBo4) & $473(4.9)$ & $57(0.9)$ & $396(23.9)$ & $12(0.9)$ \\
\hline Piperacillin and enzyme inhibitor (J01CR05) & $432(4.5)$ & $374(5.9)$ & $19(1.1)$ & $36(2.8)$ \\
\hline Ceftriaxone (Jo1DDo4) & $396(4.1)$ & $282(4.4)$ & $52(3.1)$ & $47(3.6)$ \\
\hline Vancomycin (parenteral) (Jo1XA01) & 376 (3.9) & $310(4.9)$ & $36(2.2)$ & $26(2.0)$ \\
\hline Meropenem (Jo1DHo2) & $375(3.9)$ & $322(5.1)$ & $9(0.5)$ & $29(2.2)$ \\
\hline Fluconazole (Jo2AC01) & $319(3.3)$ & $201(3.2)$ & $11(0.7)$ & $96(7.4)$ \\
\hline Levofloxacin (Jo1MA12) & $310(3.2)$ & 246 (3.9) & $13(0.8)$ & $34(2.6)$ \\
\hline Gentamicin (Jo1GBo3) & $265(2.8)$ & $151(2.4)$ & $62(3.7)$ & $46(3.6)$ \\
\hline Sulfamethoxazole and trimethoprim (J01EE01) & $235(2.5)$ & $66(1.0)$ & $7(0.4)$ & $150(11.6)$ \\
\hline Clindamycin (J01FFo1) & $228(2.4)$ & $183(2.9)$ & $34(2.1)$ & $11(0.9)$ \\
\hline Imipenem and enzyme inhibitor (J01DH51) & $141(1.5)$ & $120(1.9)$ & $11(0.7)$ & $7(0.5)$ \\
\hline
\end{tabular}

ATC: Anatomical Therapeutic Chemical; ECDC: European Centre for Disease Prevention and Control; HAl: healthcare-associated infection.

The category "Unknown indication" represented $2.9 \%$ of the total and is included in the first column. 


\section{TABLE 5}

Antimicrobial use: prevalence, indication, route of administration and reason in patient charts/notes, ECDC pilot point prevalence survey, 2010 ( $\mathrm{n}=6,875$ patients)

\begin{tabular}{|c|c|c|c|c|}
\hline & \multicolumn{2}{|c|}{ Patients with antimicrobial use $\mathrm{e}^{\mathrm{a}}$} & \multicolumn{2}{|c|}{ Antimicrobial agents } \\
\hline & $\mathrm{n}$ & $\%^{\mathrm{b}}[95 \% \mathrm{Cl}]$ & $\mathrm{n}$ & Relative $\%^{c}$ \\
\hline Total & 6,875 & $34.6[33.8-35.4]$ & 9,588 & 100 \\
\hline \multicolumn{5}{|l|}{ Indication } \\
\hline Treatment & 4,500 & $22.6[22.0-23.3]$ & 6,365 & 66.4 \\
\hline Intended for community infection & 2,919 & $14.7[14.1-15.2]$ & 3,957 & 41.3 \\
\hline Intended for hospital infection & 1,539 & $7.7[7 .--8.1]$ & 2,300 & 24.0 \\
\hline Intended for other healthcare-associated infection & 94 & $0.5[0.4-0.6]$ & 108 & 1.1 \\
\hline Surgical prophylaxis & 1,396 & $7.0[6.7-7.4]$ & 1,654 & 17.3 \\
\hline Single dose & 336 & $1.7[1.5-1.9]$ & 357 & 3.7 \\
\hline One day & 265 & $1.3[1.2-1.5]$ & 293 & 3.1 \\
\hline More than one day & 810 & $4.1[3.8-4.4]$ & 1,004 & 10.5 \\
\hline Medical prophylaxis & 979 & $4.9[4.6-5.2]$ & 1,293 & 13.5 \\
\hline Unknown indication & 211 & $1.1[0.9-1.2]$ & 276 & 2.9 \\
\hline \multicolumn{5}{|l|}{ Route of administration } \\
\hline Parenteral & 5,098 & $25.6[24.9-26.3]$ & 6,891 & 71.9 \\
\hline Oral & 2,218 & $11.2[10.7-11.6]$ & 2,648 & 27.6 \\
\hline Other/unknown & 49 & $0.2[0.2-0.3]$ & 49 & 0.5 \\
\hline \multicolumn{5}{|l|}{ Reason in patient charts/notes } \\
\hline Yes & 4,819 & $24.2[23.6-24.9]$ & 6,647 & 69.3 \\
\hline No & 2,171 & $10.9[10.5-11.4]$ & 2,939 & 30.7 \\
\hline Unknown & 2 & $0.0[0.0-0.0]$ & 2 & 0.0 \\
\hline
\end{tabular}

$\mathrm{Cl}$ : confidence interval; HAI: healthcare-associated infection.

a Patients receiving a least one antimicrobial agent.

b Prevalence of antimicrobial use in each category.

c Percentage of total number of antimicrobials (relative frequency). 
TABLE 6

Prevalence of healthcare-associated infections and antimicrobial use, by patient risk factors (standard patient-based protocol only, 50 hospitals), ECDC pilot point prevalence survey, $2010(\mathrm{n}=14,329)$

\begin{tabular}{|c|c|c|c|c|c|c|}
\hline & \multicolumn{2}{|c|}{ Surveyed patients } & \multicolumn{2}{|c|}{ Patients with HAls ${ }^{\mathrm{a}}$} & \multicolumn{2}{|c|}{ Patients with antimicrobial use } \\
\hline & $\mathrm{n}^{\mathrm{c}}$ & $\%^{d}$ & $\mathrm{n}$ & $\%^{e}$ & $n$ & $\%^{\mathrm{e}}$ \\
\hline All patients & 14,329 & 100 & 1,072 & 7.5 & 5,201 & 36.3 \\
\hline \multicolumn{7}{|l|}{ Age group (years) } \\
\hline$\ll 1$ & 746 & 5.2 & 58 & 7.8 & 181 & 24.3 \\
\hline $1-4$ & 267 & 1.9 & 18 & 6.7 & 135 & 50.6 \\
\hline $5-14$ & 393 & 2.7 & 12 & 3.1 & 148 & 37.7 \\
\hline $15-24$ & 699 & 4.9 & 30 & 4.3 & 228 & 32.6 \\
\hline $25-34$ & 1,224 & 8.5 & 34 & 2.8 & 313 & 25.6 \\
\hline $35-44$ & 1,160 & 8.1 & 75 & 6.5 & 385 & 33.2 \\
\hline $45-54$ & 1,527 & 10.7 & 106 & 6.9 & 570 & 37.3 \\
\hline $55-64$ & 2,325 & 16.2 & 212 & 9.1 & 939 & 40.4 \\
\hline $65-74$ & 2,582 & 18.0 & 241 & 9.3 & 1,012 & 39.2 \\
\hline $75-84$ & 2,481 & 17.3 & 202 & 8.1 & 903 & 36.4 \\
\hline$\geq 85$ & 925 & 6.5 & 84 & 9.1 & 387 & 41.8 \\
\hline \multicolumn{7}{|l|}{ Sex } \\
\hline Female & 7,267 & 50.7 & 456 & 6.3 & 2,364 & 32.5 \\
\hline Male & 7,062 & $49 \cdot 3$ & 616 & 8.7 & 2,837 & 40.2 \\
\hline \multicolumn{7}{|c|}{ Length of stay (days) ${ }^{f}$} \\
\hline $1-3$ & 4,622 & 32.3 & 104 & 2.3 & 1,352 & 29.3 \\
\hline $4-7$ & 3,916 & 27.3 & 300 & 7.7 & 1,608 & 41.1 \\
\hline $8-14$ & 2,824 & 19.7 & 272 & 9.6 & 1,137 & 40.3 \\
\hline$>14$ & 2,966 & 20.7 & 396 & 13.4 & 1,104 & 37.2 \\
\hline \multicolumn{7}{|c|}{ Surgical intervention since hospital admission } \\
\hline No & 10,089 & 70.4 & 569 & 5.6 & 3,163 & 31.4 \\
\hline Yes & 4,240 & 29.6 & 503 & 11.9 & 2,038 & 48.1 \\
\hline \multicolumn{7}{|l|}{ McCabe score } \\
\hline Non-fatal & 9,705 & 67.7 & 491 & 5.1 & 3,088 & 31.8 \\
\hline Ultimately fatal & 3,666 & 25.6 & 430 & 11.7 & 1,645 & 44.9 \\
\hline Rapidly fatal & 791 & 5.5 & 143 & 18.1 & 419 & 53.0 \\
\hline Missing/unknown & 167 & 1.2 & 8 & 4.8 & 49 & 29.3 \\
\hline \multicolumn{7}{|c|}{ Central vascular catheter } \\
\hline No & 12,621 & 88.1 & 651 & 5.2 & 4,033 & 32.0 \\
\hline Yes & 1,594 & 11.1 & 411 & 25.8 & 1,117 & 70.1 \\
\hline Missing/unknown & 114 & 0.8 & 10 & 8.8 & 51 & 44.7 \\
\hline \multicolumn{7}{|c|}{ Peripheral vascular catheter } \\
\hline No & 7,455 & 52.0 & 389 & 5.2 & 1,565 & 21.0 \\
\hline Yes & 6,763 & 47.2 & 674 & 10.0 & 3,592 & 53.1 \\
\hline Missing/unknown & 111 & 0.8 & 9 & 8.1 & 44 & 39.6 \\
\hline \multicolumn{7}{|l|}{ Urinary catheter } \\
\hline No & 11,702 & 81.7 & 612 & 5.2 & 3,594 & 30.7 \\
\hline Yes & 2,512 & 17.5 & 452 & 18.0 & 1,558 & 62.0 \\
\hline Missing/unknown & 115 & 0.8 & 8 & 7.0 & 49 & 42.6 \\
\hline \multicolumn{7}{|l|}{ Intubation } \\
\hline No & 13,734 & 95.8 & 888 & 6.5 & 4,775 & 34.8 \\
\hline Yes & 486 & 3.4 & 173 & 35.6 & 369 & 75.9 \\
\hline Missing/unknown & 109 & 0.8 & 11 & 10.1 & 57 & 52.3 \\
\hline
\end{tabular}

ECDC: European Centre for Disease Prevention and Control; HAI: healthcare-associated infection.

a Patients with a least one HAI.

Patients receiving at least one antimicrobial agent.

Number of patients in category.

Percentage of total (column percent).

Percentage within category (category percent).

Length of stay until onset of HAI in case of HAl during current hospitalisation. 
data collection and 1.3 for data entry. Eighteen hospitals were surveyed by an external team (either national or regional coordination staff) (Table 7).

A large variation among responding countries was identified in the workload associated with the PPS. The calculation of workload included preparation and training before the actual PPS, as well as data collection and data entry. National PPS coordinators provided on average 12.4 hours (median: 6 hours) of training to the hospital staff and spent on average an additional 6.5 hours (median: 4 hours) on answering questions during the survey. The time needed for collection and entry of data for 100 patients, was estimated at about four working days (ca. 32 hours) with the patient-based protocol and about 2.5 working days (ca. 20 hours) with the unit-based protocol. This means that performing the survey with the unit-based protocol took about $37.5 \%$ less time than with the patient-based protocol. The feasibility of the data collection was also evaluated by the analysis of missing data in the database. At the national level, 11 of 23 countries were unable to provide national hospital denominator data by hospital type as defined in the protocol. At hospital level however, the hospital type was always available and the number of beds was only missing for one hospital. Ward level data were complete because all fields were mandatory in the software. Similarly, some patient level data (age, sex, hospital admission date and medical specialty of the patient's disease or the consultant), infection data and antimicrobial use data were mandatory in the software. For the other, non-mandatory variables of the patient-based protocol ( $n=14,329$ patients), the percentage of missing values ranged from less than $1 \%$ for the presence of invasive devices, $1.2 \%$ for McCabe score, and $1.9 \%$ for surgery since admission, to $7.6 \%$ for surgery in the previous 30 days.

\section{Discussion}

The ECDC pilot PPS of HAls and antimicrobial use was successfully performed from May to October 2010 in 66 acute care hospitals from 23 countries. In total, 19,888 patients were surveyed. The number of participating hospitals was higher than the anticipated minimum of 25 hospitals. The collected data allowed for the estimation of the prevalence of HAls and antimicrobial use, which was the primary objective set by ECDC. Both the patient-based protocol, preferred by the majority $(76 \%)$ of hospitals, and the unit-based protocol (applied by $24 \%$ of hospitals) provided the necessary data.

\section{Main study limitations}

An important limitation of our study is that the hospitals participating in this ECDC pilot PPS were not representative of the total hospital patient population in the EU. Hospitals were not randomly selected, and

\section{TABLE 7}

Type of healthcare workers involved in data collection and data entry for the ECDC pilot point prevalence survey, 2010 $(\mathrm{n}=50$ hospitals)

\begin{tabular}{|c|c|c|c|c|c|c|}
\hline \multirow[t]{2}{*}{ Type of healthcare worker } & \multicolumn{2}{|c|}{$\begin{array}{c}\text { Hospitals where this type of } \\
\text { healthcare worker was involved }\end{array}$} & \multicolumn{2}{|c|}{$\begin{array}{l}\text { Involved in } \\
\text { data collection }\end{array}$} & \multicolumn{2}{|c|}{$\begin{array}{l}\text { Involved in } \\
\text { data entry }\end{array}$} \\
\hline & $\mathrm{n}$ & $\%^{a}$ & $\mathrm{n}$ & $\%^{\mathrm{b}}$ & $\mathrm{n}$ & $\%{ }^{b}$ \\
\hline Infection control nurse & 25 & 50 & 25 & 100 & 9 & 36 \\
\hline Infection control physician or equivalent & 31 & 62 & 31 & 100 & 12 & 39 \\
\hline Ward nurse & 18 & 36 & 18 & 100 & 0 & 0 \\
\hline Ward physician & 15 & 30 & 15 & 100 & 0 & 0 \\
\hline Infectious disease physician & 12 & 24 & 12 & 100 & 3 & 25 \\
\hline Hospital microbiologist & 6 & 12 & 6 & 100 & 3 & 50 \\
\hline Medical specialist trainee & 10 & 20 & 10 & 100 & 2 & 20 \\
\hline Hospital pharmacist & 6 & 12 & 6 & 100 & 1 & 17 \\
\hline Infection control link nurse & 5 & 10 & 5 & 100 & 1 & 20 \\
\hline Data nurse & 4 & 8 & 3 & 75 & 2 & 50 \\
\hline Nurse aid & 1 & 2 & 0 & 0 & 1 & 100 \\
\hline Medical student & 1 & 2 & 1 & 100 & 0 & 0 \\
\hline Other hospital staff & 10 & 20 & 6 & 60 & 6 & 60 \\
\hline National PPS coordination staff & 13 & 26 & 12 & 92 & 6 & 46 \\
\hline Regional PPS coordination staff & 5 & 10 & 5 & 100 & 2 & 40 \\
\hline Other & 6 & 12 & 4 & 67 & 3 & 50 \\
\hline
\end{tabular}

ECDC: European Centre for Disease Prevention and Control; PPS: point prevalence survey.

a Percentage of total number of responding hospitals $(n=50)$.

Percentage of number of healthcare workers in category. 
tertiary or teaching hospitals were overrepresented in the study sample (52.3\% instead of less than $10 \%$, according to available national hospital statistics). This selection had consequences both for the results of the feasibility test of the protocol and for the interpretation of the epidemiological results of the study (see below).

In addition, since inference from the epidemiological study results to the total acute care hospital population in Europe was not an objective of the pilot study, we did not apply any statistical methods that could take into account the effects of the hierarchical design of the study (e.g. regions within countries, hospitals within regions, wards within hospitals, and types of patients within wards). Methods such as multilevel modelling for risk factor analysis and complex survey analysis to adjust confidence intervals for the prevalence estimates at the national and EU level will be used to analyse the EU-wide PPS of HAls and antimicrobial use that was conducted in 2011-12. The pilot study database was also used to estimate the expected design effect (DEFF) for different average sizes of hospitals (patient clusters) in order to estimate the required sample size for each country in the EU-wide PPS [14]. The overall DEFF in the pilot PPS was 5.3 for the prevalence of HAls and $\mathbf{2 2 . 7}$ for the prevalence of antimicrobial use, indicating indeed that the sample design for representative samples at the national level should be adjusted for the important clustering of the main survey outcomes within the hospitals.

\section{Feasibility study}

A minority of respondents to the feasibility questionnaire mentioned that the participating included hospitals in their country had had experience in performing PPSs and that it is unlikely that randomly selected hospitals would be able to participate in an ECDC EU-wide PPS. ECDC therefore provided training material to help national contact points improve the skills of hospital staff during preparation of the future EU-wide PPS. Part of this training material was already available before the pilot PPS and was used to organise the training of the hospital contact points in the current study.

Training is also of key importance for the standardisation of data collection in participating hospitals, including interpretation of the case definitions. The large variation in the number and type of HCWs involved in data collection for this pilot PPS (Table 7) illustrates the challenge of standardising data collection for an EU-wide PPS. For example, failure to consult the clinical team in charge of patient care during data collection, as recommended in the protocol, may impact on the ascertainment of variables such as the medical specialty of the patient's disease or of the consultant in charge of the patient (patient/consultant specialty), the McCabe score, the physician's motive for prescribing antimicrobials, or even the signs and symptoms of a suspected HAI. The fact that ward staff was not involved in the data collection in more than half of the hospitals may indeed indicate that physicians were not sufficiently consulted. Also, the fact that in 18 of the 66 hospitals the survey was performed by an external team may indicate that the pilot PPS was not always performed in real-life conditions since this scenario is unlikely to be a feasible option for the ECDC EU-wide PPS or a full-scale national PPS.

Another frequently mentioned feasibility issue was the difficulty to categorise hospitals at the national level according to the hospital types defined in the protocol (primary, secondary, tertiary and specialised). Information on hospital categories used in the different countries are needed for the future EU-wide PPS to ensure that all categories are represented proportionally in the national representative sample. In addition, national denominator data (e.g. number of hospitals and discharges per year) by hospital type would be needed (i) to extrapolate the PPS results by hospital type (category-specific burden estimates), and (ii) to adjust the national and EU burden estimates in case hospital types are not proportionally represented in the national samples. Only 13 of 23 countries were able to provide some categorisation of their national list of hospitals according to the categories of the protocol, using the national hospital type categories.

Therefore, for the purpose of drawing a representative systematic sample of hospitals for the EU-wide PPS, the standardised EU types of hospitals were replaced by the national hospital categories in the final protocol of the ECDC EU-wide PPS. This means that, for the analysis of the data collected in the ECDC EU-wide PPS, it will not be possible to stratify or adjust the estimates of the burden of HAls and antimicrobial use (based on extrapolation to the total national denominator data) according to types of hospitals.

\section{Patient-based versus unit-based protocol}

Despite a higher workload, the patient-based protocol was used more often than the unit-based protocol, thus allowing a better description of patients and invasive procedures. During an expert meeting held in Brussels in November 2010, it was recommended that PPSs of HAls and antimicrobial use should be carried out at least once every five years, and the patient-based protocol was selected as the preferred methodology for future PPSs [43]. This expert recommendation is anticipating the fact that, because of hospital changes and medical advances, a patient-based protocol would be required to allow for detailed adjustment for patient case-mix. The patient-based protocol allows for assessment of the prevalence of HAls and antimicrobial use according to the presence or absence of various risk factors and enables categorisation of hospitals by patient case-mix at national and/or European level. Indeed, adjustment for patient case-mix has been used in other studies, including for outcomes in intensive care $[44,45]$ and surgical patients [46], and for comparing HAI rates [47]. Patient-based PPSs can also be used to identify patient-related factors that influence 
the prevalence of HAls and thus help focus surveillance and infection prevention initiatives [48].

The unit-based protocol, however, will be kept, to offer a less labour-intensive option for countries and hospitals where human resources are limited. This protocol might also be more appropriate for very large hospitals and in situations that require repeated PPSs at short intervals. A limitation is that its only denominator variable is the number of patients per ward, for the total ward and for the specialty of each patient's disease within each ward. This only allows an estimation of the prevalence of HAls and antimicrobial use by ward or patient's disease specialty.

The ECDC pilot PPS also aimed at identifying any issue with the methodology that required modification, e.g. availability of data for any of the collected variables, or applicability of the case definitions for HAls, before finalising the patient-based and unit-based protocols for the ECDC EU-wide PPS that was started in May 2011. Denominator data in the unit-based protocol did not require any modification whereas, for the patientbased protocol, the only variable that was difficult to obtain was 'surgery in the previous 30 days'. This variable also overlapped with 'surgery since admission' which was less difficult to determine. It was therefore decided that, for the ECDC EU-wide PPS, the data for the variable 'surgery in previous 30 days' would eventually not be collected [14]. With respect to case definitions for HAls, a major change was the decision to add the case definition of clinical sepsis in adults, because possible bloodstream infections for which microbiological results were not yet available at the time of the PPS would otherwise remain unreported.

\section{Epidemiological results}

The two sections of the ECDC pilot PPS, i.e. HAls and antimicrobial use, were independent of each other and did not follow the same definitions: data on HAls were recorded following standardised epidemiological case definitions, whilst the indication for antimicrobial use was based on clinical judgment by the treating physician. For example, a patient could have been registered in the antimicrobial use section as receiving antimicrobials with the intention to treat a hospital infection, but the same patient did not fulfil the case definition for $\mathrm{HAl}$ and therefore was not included as having a $\mathrm{HAl}$ in the HAl section. Conversely, a patient may have presented the symptoms and signs of a HAI, but not have been treated with an antimicrobial. Hence, among other things, the different proportions for hospitalacquired pneumonia in Table 2 .

While the protocol for the EU-wide PPS foresees a representative systematic random sample of hospitals in the participating countries [14], the data collected through this ECDC pilot PPS were not representative of the epidemiology of HAIs in the EU and the results must be interpreted with caution. The HAI prevalence of $7.1 \%$ (inter-quartile range: $4.2-9.4 \%$ ) observed in our study is likely to be slightly overestimated because of the overrepresentation of tertiary hospitals which had a higher prevalence of HAls (7.4\%) than secondary and primary hospitals. Nevertheless, the overall HAI prevalence in this pilot PPS is comparable to that reported in other European studies $[9,11,12]$ and to the European prevalence of HAls of $7.1 \%$, estimated by ECDC based on a review of 30 national or multicentre PPSs in 19 countries in its Annual Epidemiological Report for 2008 [1]. The range of reported prevalence results in studies that used CDC definitions for HAls in non-EU countries, ranged from $4.9 \%$ in Mauritius in 1992 to $19.1 \%$ in Malaysia in 2001 [30]. Such a wide range in the prevalence of HAls could be explained by differences in methodology and patient case-mix, and should not immediately be interpreted as an indication of variations in performance.

The distribution of isolated microorganisms in patients with HAI in this pilot PPS was also similar to that previously reported in the review of national or multicentre point prevalence surveys, with $E$. coli being most frequent [1]. The fact that only $59.1 \%$ of the HAls were documented by microbiological results was also in line with previous findings $[9,49,50]$ and was expected because, with few exceptions, case definitions of HAls are primarily based on clinical criteria.

With respect to antimicrobial use, the ECDC pilot PPS showed a prevalence about $5 \%$ higher than shown by previous ESAC hospital PPSs using an identical methodology $[23,25,26]$. Nevertheless, the ranking order of the most used antimicrobials was comparable to that observed in ESAC hospital PPSs, with the various betalactams (penicillins, cephalosporins and carbapenems) accounting for more than half of all antimicrobials used. Other PPSs have reported a wide range of prevalence of antimicrobial use in acute care hospitals due to varying inclusion criteria [23].

A final aspect that should be considered for the interpretation of the epidemiological results of this and future surveys is the fact that the ECDC pilot PPS was not performed on a single day. For feasibility reasons, hospitals were allowed to organise the PPS within a period of three weeks, with the only restriction being that a ward had to be surveyed on a single day. In practice, hospitals and countries performed the pilot PPS survey from May until October 2010. For the EU-wide PPS, ECDC agreed with the national PPS coordinating centres in November 2010 on three possible periods to organise the first national PPS using the ECDC methodology [43]. These periods (May-June 2011, September-October 2011 and May-June 2012) were selected to avoid the winter period because of the higher incidence of respiratory tract infections and the summer holiday period because shortage of staff and lower activity in the hospital during this period could influence the practical organisation as well as the main outcomes of the survey. Despite these considerations, the potentially long time span between the different 
surveys may influence comparability of the results between hospitals, regions or countries, e.g. because of rapidly changing incidences of HAls with epidemic pathogens or the implementation of local or national infection control measures.

In conclusion, the ECDC pilot PPS methodology was successfully implemented by the national contact points, the hospital contact points and the HCWs involved in data collection and entry in the participating hospitals, without any major feasibility issues that could have led hospitals to cancel their participation. The pilot PPS showed that the aim of estimating the burden of HAls and antimicrobial use in European acute care hospitals was realistic, irrespective of the protocol used. The patient-based protocol, even if more resource-intensive, was used more widely and provided more detailed and valuable data than the unit-based protocol. It was therefore selected as the preferred option for the ECDC EU-wide PPS of HAls and antimicrobial use.

\section{Funding}

This pilot survey was funded by the European Centre for Disease Prevention and Control (ECDC) following an open call for tender procedure ("Support to the pilot point prevalence survey of healthcare-associated infections and antimicrobial use in European acute care hospitals", 0J/2010/03/22PROC/2010/012), which was awarded to a consortium led by the University of Antwerp in collaboration with the French Institut de Veille Sanitaire (InVS) and the Belgian Scientific Institute of Public Health (WIV-ISP) (specific service contract ECD.2172).

National Contact Points for the ECDC pilot point prevalence survey

Belgium: Sofie Vaerenberg, Mathijs-Michiel Goossens; Bulgaria: Rossitza Vatcheva-Dobrevska; Croatia: Smilja Kalenic; Cyprus: Avgi Hadjiloukas; Czech Republic: Hana Smejkalova, Jan Šturma; Estonia: Pille Märtin; Finland: Outi Lyytikäinen, Tommi Kärki; France: Bruno Coignard; Germany: Petra Gastmeier; Greece: Achilleas Gikas; Hungary: Karolina Böröcz; Italy: Maria Luisa Moro; Latvia: Uga Dumpis; Lithuania: Rolanda Valinteliene, Jolanta Ašembergienè; Luxembourg: Robert Hemmer; Malta: Michael Borg; Norway: Hanne-Merete Eriksen; Poland: Tomasz Ozorowski; Portugal: Ana Cristina Costa; Romania: Roxana Ioana Serban; Slovakia: Mária Štefkovičová, Slavka Litvová; Slovenia: Irena Klavs, Jana Kolman, Nejc Bergant, Tanja Kustec; Spain: Josep Vaqué, Angel Asensio; United Kingdom-Scotland: Jacqui Reilly.

Hospital Contact Points for the ECDC pilot point prevalence survey and their respective hospitals

Belgium: Christine Laurent (ULB Erasme), Hilde Jansens (UZA), Katia Verhamme (OLV Aalst), Benedicte Delaere (UCL Mont-Godinne), Annemarie Van Den Abeele (St Lucas Gent), Reinoud Cartuyvels (Jessa ZH - campus Virga Jesse), Soraya Cherifi, Sylvie Arias Lopez (CHU Brugmann); Bulgaria: Rossitza Vatcheva-Dobrevska (2nd Multiprofile Active Treatment Hospital (MBAL) \& MBAL "At. Dafovski” AD-Kardjali); Croatia: Zrinka Bošnjak (University Hospital Centre Zagreb), Domagoj Drenjancevic (University Hospital Centre Osijek); Cyprus: Maria Kontou (Nicosia general hospital), Ioannis Demetriades (Larnaca general hospital), Emmelia Vounou (Limassol general hospital); Czech Republic: Ladislava Matějíčková (Městská nemocnice v Litoměřicích), Jana Prattingerova (Krajska nemocnice Liberec, a.s.); Estonia: Pille Märtin (West Tallinn Central Hospital), Piret Mitt (Tartu University Hospital); Finland: Mari Kanerva (Meilahden sairaala, Töölön sairaala, Silmäja korvasairaala, Lasten- ja nuorten sairaala, Iho- ja allergiasairaala, Naistenklinikka, Kätilöopiston sairaala, Syöpätautien klinikka, Kirurginen sairaala, Jorvin sairaala, Peijaksen sairaala, Länsi-Uudenmaan sairaala, Porvoon sairaala, Lohjan sairaala \& Hyvinkään sairaala); France: Serge Alfandari (Centre Hospitalier G. Dron, Tourcoing), Philippe Vanhems, Thomas Benet (Hôpital Edouard-Herriot, Hospices Civils de Lyon), Bruno Grandbastien (CHRU de Lille); Germany: Nadine Mönch (Evangelische Elisabeth Klinik Krankenhausbetriebs gGmbH); Greece: Achilleas Gikas (University hospital of Heraklion); Hungary: Emese Szilágyi (National Center for Cardiology), Andrea Kurcz (Szt. Lukacs county hospital); Italy: Angelo Pan (Istituti Ospitalieri di Cremona-Presidio Ospedaliero di Cremona), Rosario Canino (Istituti Ospitalieri di Cremona-Ospedale di Oglio Po), Grazia Tura (Ospedale Sacra Famiglia Novafeltria), Liana Signorini (Azienda Ospedaliera Spedali Civili di Brescia); Latvia: Uga Dumpis (Stradins University Hospital), Mārīte Kūla (Liepaja Regional hospital); Lithuania: Viljaras Reigas (Klaipèdos Children Hospital); Audra Žygelienè (Biržų Hospital), Jolanta Falkovska (Vilnius University Children Hospital, Surgery Center); Luxembourg: Robert Hemmer (Centre Hospitalier de Luxembourg); Malta: Elizabeth A. Scicluna (Mater Dei Hospital); Poland: Tomasz Ozorowski (Provincial Hospital, Poznan); Portugal: Carlos Palos (Hospital da Luz), Etelvina Ferreira (Hospital dos Lusíadas - HPP Saúde); Romania: Ghita Camelia (Fundeni Clinical Institute for digestive diseaeses and liver transplantations); Slovenia: Tatjana Lejko Zupanc (University Medical Centre Ljubljana); Božena Kotnik Kevorkijan (University Medical Centre Maribor); Slovakia: Henrieta Hudečková (Martin Faculty Hospital), Andrea Kološová (Forlife, n.o. - General Hospital); Spain: Josep Vaqué (Hospital Universitario Vall d'Hebron); Angel Asensio (Hospital Universitario Puerta de Hierro), Angela Rincón Carlavilla (Hospital General Universitario de Alicante), Nieves López Fresneña (Hospital del Henares), Margarita Viciola Garcia (Hospital de San Eloy); United Kingdom, Scotland: Shona Cairns (Monklands General Hospital). 


\section{References}

1. European Centre for Disease Prevention and Control (ECDC). Annual epidemiological report on communicable diseases in Europe 2008. Stockholm: ECDC; 2008. Available from: http:// ecdc.europa.eu/en/publications/Publications/0812_SUR_ Annual Epidemiological Report_2008.pdf

2. Agodi A, Auxilia F, Barchitta M, Brusaferro S, D’Alessandro D, Montagna MT, et al. Building a benchmark through active surveillance of intensive care unit-acquired infections: the Italian network SPIN-UTI. J Hosp Infect. 2010;74(3):258-65.

3. Lambert M, Suetens C, Savey A, Palomar M, Hiesmayr M, Morales I, et al. Clinical outcomes of healthcare-associated infections and antimicrobial resistance in patients admitted to European intensive-care units: a cohort study. Lancet Infect Dis. 2011;11(1):30-8.

4. Wilson J, Ramboer I, Suetens C. Hospitals in Europe link for infection control through surveillance (HELICS). Inter-country comparison of rates of surgical site infection--opportunities and limitations. J Hosp Infect. 2007;65(Suppl 2):165-70.

5. Suetens C, Morales I, Savey A, Palomar M, Hiesmayr M, Lepape $A$, et al. European surveillance of ICU-acquired infections (HELICS-ICU): Methods and main results. J Hosp Infect. 2007;65 (Suppl 2):171-3.

6. Suetens C, Savey A, Labeeuw J, Morales I. The ICUHELICS programme: Towards European surveillance of hospital-acquired infections in intensive care units. Euro Surveill. 2002;7(9):pii=359. Available from: http://www. eurosurveillance.org/ViewArticle.aspx?Articleld=359

7. Improving Patient Safety in Europe (IPSE). The IPSE report 2005-2008. Lyon: Université Claude Bernard Lyon1; November 2009]. Available from http://www.ecdc.europa.eu/en/ activities/surveillance/HAI/Documents/0811_IPSE_Technical Implementation_Report.pdf

8. Gravel D, Taylor G, Ofner M, Johnston L, Loeb M, Roth VR, et al. Point prevalence survey for healthcare-associated infections within Canadian adult acute-care hospitals. J Hosp Infect. 2007;66(3):243-8.

9. Lanini S, Jarvis WR, Nicastri E, Privitera G, Gesu G, Marchetti F, et al. Healthcare-associated infection in Italy: Annual pointprevalence surveys, 2002-2004. Infect Control Hosp Epidemiol. 2009;30(7):659-65

10. Struwe J, Dumpis U, Gulbinovic J, Lagergren Å, Bergman U. Healthcare associated infections in university hospitals in Latvia, Lithuania and Sweden: a simple protocol for quality assessment. Euro Surveill. 2006;11(7):pii=640. Available from: http://www.eurosurveillance.org/ViewArticle. aspx?Articleld $=640$

11. The RAISIN Working Group. "RAISIN" - a national programme for early warning, investigation and surveillance of healthcare-associated infection in France. Euro Surveill. 2009;14(46): pii=19408. Available from: http://www. eurosurveillance.org/ViewArticle.aspx?Articleld $=19408$

12. Reilly J, Stewart S, Allardice GA, Noone A, Robertson C, Walker A, Coubrough S. Results from the Scottish national HAI prevalence survey. J Hosp Infect. 2008;69:62-8.

13. Suetens C, Ammon A, Weist K, Sodano L, Monnet DL. Review of methods of national prevalence surveys of healthcareassociated infections in 17 European countries. European Congress of Clinical Microbiology and Infectious Diseases (ECCMID); 16-19 May 2009; Helsinki, Finland. Clin Microbiol Infect. 2009;15(s4):P.624.

14. European Centre for Disease Prevention and Control (ECDC). Point prevalence survey of healthcare-associated infections and antimicrobial use in European acute care hospitals. Protocol version 4.3. Full scale survey and codebook. Stockholm: ECDC: 2012. Available from: http://www.ecdc europa.eu/en/activities/surveillance/HAl/about_HAI-Net/ Pages/PPS.aspx

15. Müller-Pebody B, Muscat M, Pelle B, Klein BM, Brandt CT, Monnet DL. Increase and change in pattern of hospital antimicrobial use, Denmark, 1997-2001. J Antimicrob Chemother. 2004;54(6):1122-6.

16. Vander Stichele RH, Elseviers MM, Ferech M, Blot S, Goossens $\mathrm{H}$. Hospital consumption of antibiotics in 15 European countries: results of the ESAC retrospective data collection (1997-2002). J Antimicrob Chemother. 2006;58(1):159-67.

17. de Man P, Verhoeven BA, Verbrugh HA, Vos MC, van den Anker JN. An antibiotic policy to prevent emergence of resistant bacilli. Lancet. 2000;355(9208):973-8.

18. Cooke DM, Salter AJ, Phillips I. The impact of antibiotic policy on prescribing in a London teaching hospital. a oneday prevalence survey as an indicator of antibiotic use. Antimicrob Chemother. 1983;11(5):447-53.

19. Berild D, Ringertz SH, Lelek M. Appropriate antibiotic use according to diagnoses and bacteriological findings: Report of
12 point-prevalence studies on antibiotic use in a University hospital. Scand J Infect Dis. 2002;34(1):56-60.

20. Ufer M, Radosević N, Vogt A, Palcevski G, Francetić I, Reinalter SC, et al. Antimicrobial drug use in hospitalised paediatric patients: a cross-national comparison between Germany and Croatia. Pharmacoepidemiol Drug Saf. 2005;14(10): 735-9.

21. Usluer G, Ozgunes I, Leblebicioglu H. A multicenter pointprevalence study: antimicrobial prescription frequencies in hospitalized patients in Turkey. Ann Clin Microbiol Antimicrob. 2005;4:16.

22. Ciofi Degli Atti ML, Raponi M, Tozzi AE, Ciliento G, Ceradini J, Langiano T. Point prevalence study of antibiotic use in a paediatric hospital in Italy. Euro Surveill. 2008;13(41):pii=19003. Available from: http://www. eurosurveillance.org/ViewArticle.aspx?Articleld=19003

23. Ansari F, Erntell M, Goossens H, Davey P. The European surveillance of antimicrobial consumption (ESAC) pointprevalence survey of antibacterial use in 20 European hospitals in 2006. Clin Infect Dis. 2009;49(10):1496-504.

24. Amadeo B, Zarb P, Muller A, Drapier N, Vankerckhoven $V$, Rogues A, et al. European surveillance of antibiotic consumption (ESAC) point prevalence survey 2008: Paediatric antimicrobial prescribing in 32 hospitals of 21 European countries. J Antimicrob Chemother. 2010;6(10)5:2247-52.

25. Zarb P, Amadeo B, Muller A, Drapier N, Vankerckhoven $V$, Davey $P$, et al. Identification of targets for quality improvement in antimicrobial prescribing: The web-based ESAC point prevalence survey 2009. J Antimicrob Chemother. 2011;66(2):443-9.

26. Zarb P, Goossens H. European surveillance of antimicrobial consumption (ESAC): Value of a point-prevalence survey of antimicrobial use across Europe. Drugs. 2011;71(6):745-55.

27. Zarb P, Ansari F, Muller A, Vankerckhoven V, Davey PG, Goossens H. Drug utilization 75\% (DU75\%) in 17 European hospitals (2000-2005): Results from the ESAC-2 hospital care sub project. Curr Clin Pharmacol. 2011;6(1):62-70.

28. Ang L, Laskar R, Gray JW. A point prevalence study of infection and antimicrobial use at a UK children's hospital. J Hosp Infect. 2008;68(4):372-4.

29. O’Neill E, Morris-Downes M, Rajan L, Fitzpatrick F, Humphreys $\mathrm{H}$, Smyth E. Combined audit of hospital antibiotic use and a prevalence survey of healthcare-associated infection. Clin Microbiol Infect. 2010;16(5):513-5.

30. Ider BE, Clements A, Adams J, Whitby M, Muugolog T. Prevalence of hospital-acquired infections and antibiotic use in two tertiary Mongolian hospitals. J Hosp Infect. 2010;75(3):214-9.

31. Hajdu A, Samodova OV, Carlsson TR, Voinova LV, Nazarenko SJ, Tjurikov AV, et al. A point prevalence survey of hospital-acquired infections and antimicrobial use in a paediatric hospital in north-western Russia. J Hosp Infect. 2007;66(4):378-84

32. Maugat S, Thiolet J, L'Hériteau F, Gautier C, Tronel H, Metzger $M$, et al. Prévalence des traitements antibiotiques dans les établissements de santé, France 2006 [Prevalence of antibiotic treatments in healthcare facilities, France, 2006]. Bull Epidemiol Hebd. 2007;51-52:432-7. French. Available from: http://opac.invs.sante.fr/doc_num.php?explnum_id $=3474$

33. 33. Council of the European Union. Council Recommendation of 9 June 2009 on patient safety, including the prevention and control of healthcare associated infections (2009/C 151/01). Available from: http://eur-lex.europa.eu/LexUriServ/ LexUriServ.do?uri=0J:C:2009:151:0001:0006:EN:PDF

34. Council of the European Union. Council Recommendation of 15 November 2001 on the prudent use of antimicrobial agents in human medicine (2002/77/EC). Available from: http://eur-lex. europa.eu/LexUriServ/LexUriServ.do?uri=0J:L:2002:034:0013 :0016:EN:PDF

35. Hospital in Europe Link for Infection Control through Surveillance (HELICS). Surveillance of surgical site infections. Protocol version 9.1. Lyon: HELICS; Sept 2004. Available from: http://www.ecdc.europa.eu/en/activities/surveillance/HAl/ Documents/0409_IPSE_SSI_protocol.pdf

36. Kuijper EJ, Coignard B, Tüll P, ESCMID Study Group for Clostridium difficile; EU Member States; European Centre for Disease Prevention and Control. Emergence of Clostridium difficile-associated disease in North America and Europe. Clin Microbiol Infect. 2006;12(Suppl 6): 2-18.

37. Nosocomial infection surveillance system for preterm infants on neonatology departments and intensive care units (NeoKISS). Protokoll.Surveillance nosokomialer Infektionen bei Frühgeborenen mit einem Geburtsgewicht $<1.500$ g. [Protocol. Surveillance of nosocomial infections in preterm infants with a birth weight $<1,500 \mathrm{~g}]$. Berlin: Institut für Hygiene und Umweltmedizin, Charité; Dec 2009. German. Available 
from: http://www.nrz-hygiene.de/fileadmin/nrz/download/ NEOKISSProtokoll221209.pdf

38. Hospital in Europe Link for Infection Control through Surveillance (HELICS). Surveillance of nosocomial infections in intensive care units. Protocol version 6.1. Lyon: HELICS; Sept 2004. Available from:http://www.ecdc.europa.eu/en/activities/ surveillance/HAI/Documents/0409_IPSE_ICU_protocol.pdf

39. Geffers C, Baerwolff S, Schwab F, Gastmeier P. Incidence of healthcare-associated infections in high-risk neonates: results from the German surveillance system for very-low-birthweight infants. J Hosp Infect. 2008;68(3):214-21.

40. Horan TC, Andrus M, Dudeck MA. CDC/NHSN surveillance definition of health care-associated infection and criteria for specific types of infections in the acute care setting. Am J Infect Control. 2008;36(5):309-32.

41. World Health Organization (WHO) Collaborating Centre for Drug Statistics Methodology. The ATC/DDD system: International language for drug utilization research. Oslo: WHO Collaborating Centre for Drug Statistics Methodology; Oct 2007. Available from: http://www.fhi.no/dav/aofb3024e7.pdf

42. McCabe WR, Jackson GG. Gram-negative bacteremia: I. Etiology and ecology. Arch Intern Med. 1962;110:847-53.

43. Goossens H. Expert-proposed European strategies to monitor and control infection, antibiotic use, and resistance in healthcare facilities. Lancet Infect Dis. 2011;11(5):338-40.

44. Pappachan JV, Millar B, Bennett ED, Smith GB. Comparison of outcome from intensive care admission after adjustment for case mix by the APACHE III prognostic system. Chest. 1999;115(3):802-10.

45. Rowan KM, Kerr JH, Major E, McPherson K, Short A, Vessey MP. Intensive Care Society's APACHE II study in Britain and Ireland--II: outcome comparisons of intensive care units after adjustment for case mix by the American APACHE II method. BMJ. 1993;307(6910):977-81.

46. McArdle CS, Hole DJ. Outcome following surgery for colorectal cancer: analysis by hospital after adjustment for case-mix and deprivation. Br J Cancer. 2002;86(3):331-5.

47. Sax H, Pittet D. Interhospital differences in nosocomial infection rates: importance of case-mix adjustment. Arch Intern Med. 2002;162(21):2437-42.

48. Reilly J, Stewart S, Allardice G, Cairns S, Ritchie L, Bruce J. Evidence-based infection control planning based on national healthcare-associated infection prevalence data. Infect Control Hosp Epidemiol. 2009;30(2):187-9.

49. Valintiliene R, Gailiene G, Berzanskyte A. Prevalence of healthcare-associated infections in Lithuania. J Hosp Infect. 2012;80(1):25-30.

50. Lyytikäinen O, Kanerva M, Agthe N, Möttönen T, Ruutu P; Finnish Prevalence Survey Study Group. Healthcare-associated infections in Finnish acute care hospitals: a national prevalence survey, 2005. J Hosp Infect. 2008:69(3):288-94. 